\title{
Biomarkers of prolonged exposure to microcystin-LR in mice
}

\author{
Daniela Sedan $^{\text {b }}$, Leda Giannuzzi ${ }^{\text {a, b }}$, Lorena Rosso ${ }^{\text {b }}$, Carlos Alberto Marra ${ }^{\text {, }}$ \\ Darío Andrinolo ${ }^{\mathrm{b}, *}$ \\ ${ }^{a}$ CIDCA (Centro de Investigación y Desarrollo en Criotecnología de Alimentos), Universidad Nacional de La Plata UNLP, \\ CCT-La Plata CONICET, Argentina \\ ' Área de Toxicología, Facultad de Ciencias Exactas, Universidad Nacional de La Plata UNLP, 1900 La Plata, Argentina \\ ${ }^{\mathrm{c}}$ INIBIOLP (Instituto de Investigaciones Bioquímicas de La Plata), Cátedra de Bioquímica y Biología Molecular de la Facultad de Ciencias \\ Médicas de la Universidad Nacional de La Plata UNLP, CCT-La Plata CONICET, Argentina
}

\section{A R T I C L E I N F O}

\section{Article history:}

Received 20 November 2012

Received in revised form 27 February 2013

Accepted 1 March 2013

Available online 15 March 2013

\section{Keywords:}

Microcystins

Prolonged exposure

Biomarkers

Mice

\begin{abstract}
A B S T R A C T
The effects of prolonged exposure to microcystins (MCs) on health are not yet sufficiently understood and this type of poisoning is often undiagnosed. Even though chronic exposure has been linked with liver cancer and alterations have been described in liver damage marker enzymes in exposed populations, there are not profile parameters that indicate prolonged exposure to microcystins.

The aim of this work is to determine, based on an animal model of prolonged exposure to successive i.p. doses of $25 \mu \mathrm{g}$ MC-LR/kg body weight, several plasma parameters which could be useful as exposure biomarkers.

Hemoglobin $(\mathrm{Hb})$ and methemoglobin (MetHb) levels were determined on blood samples. We also studied plasma levels of hydroperoxides (ROOHs), $\alpha$-tocopherol, glutathione and lipid profile as well as superoxide dismutase (SOD) and catalase (CAT) erythrocyte activities. In addition, the determination of MC-LR levels in liver, kidney, plasma, urine and feces of treated mice was carried out. We found that alteration in MetHb, ROOHs, glutathione, $\alpha$-tocopherol levels, SOD activity and plasma lipid profile, correlates with those expected if the alteration derived from hepatic damage. The alterated plasma paramenters together with MC-LR determination could be used as biomarkers, helpful tools in screening and epidemiological studies.
\end{abstract}

(c) 2013 Elsevier Ltd. All rights reserved.

\section{Introduction}

Cyanobacterial blooms in natural waters, causing serious water pollution and public health hazard to humans and livestock, have become a worldwide problem (Carmichael, 1997; WHO, 2004). Of all the algal toxins, microcystins (mainly microcystin-LR, RR and YR) are the most toxic and abundant species (Carmichael, 1994). Microcystins

\footnotetext{
* Corresponding author.

E-mail addresses: dandrinolo@yahoo.com, dandrinolo@exactas.unlp. edu.ar (D. Andrinolo).
}

(MCs) are cyclic heptapeptides, composed of seven amino acids. More than 80 variants are known (Sivonen and Jones, 1999), many of which are potent hepatotoxins, and it has been demonstrated that MCs have toxic effects to various organs in animals (Cazenave et al., 2006; Soares et al., 2007; Zhao et al., 2009).

The two main MCs toxic mechanisms are their ability to inhibit protein phosphatases 1 and 2A (Yoshizawa et al., 1990) and enhance intracellular production of reactive oxygen species (ROS) (Ding et al., 1998), which results in significant imbalances in protein phosphorylation status and redox homeostasis (Gehringer, 2004; Ding et al., 2000, 2003). This scenario leads to hepatocyte cytoskeleton disruption (Ohta et al., 1992; Toivola et al., 1994), 
deregulation of cell division (Carmichael, 1994; Guzman et al., 2003), DNA damage (Ding et al., 1999; Lezcano et al., 2012) tumor promotion (Falconer, 1991; Falconer and Humpage, 1996), lipid peroxidation and hepatic lipid profile alterations (Andrinolo et al., 2008; Sedan et al., 2010), mitochondrial membrane permeability changes (Ding et al., 2000, 2001; Moreno et al., 2003) and apoptosis (Gehringer, 2004; Lezcano et al., 2012) according to the level, time and/or route of exposure.

Acute MCs poisoning in mammals is characterized by disruption of hepatic architecture, leading to massive intrahepatic hemorrhage and death in a few hours (Carmichael, 1994). On the other hand, chronic exposure studies reveal a wide range of hepatocyte damage like cytosolic vacuolation, single-cell necrosis, fibrosis, apoptosis and tumor promotion (Ito et al., 1997; Solter et al., 1998; Guzman and Solter, 2002; Andrinolo et al., 2008; Lezcano et al., 2012).

MCs have been associated with damage to human and animal health causing different and characteristic patterns of damage that depend on the route, intensity and time of exposure. Reported diseases caused by MCs vary in severity, ranging from death due to liver failure (Caruaru syndrome) (Jochimsen et al., 1998) and gastrointestinal syndromes (Tisdale, 1931; Zilberg, 1966; Lippy and Erb, 1976; Teixera et al., 1993; Annadotter et al., 2001) to skin damage, respiratory problems (Giannuzzi et al., 2011; Turner et al., 1990) and liver cancer (Amstrong, 1980; Yu, 1989; Bell and Codd, 1994).

Although acute poisoning represents the most characteristic form of damage associated to microcystin-LR (MCLR) intoxications, prolonged exposure to sub-lethal doses could frequently generate health problems (Dietrich et al., 2007; Chen et al., 2009). Most studies reported high incidence of primary liver cancer associated to prolonged ingestion of MCs contaminated water (Yu, 1995; Xia, 2002) or even death induced by progressive liver failure associated with chronic intake of dietary supplements of Aphanizomenon. flos-aquae contaminated with MC-LR (Dietrich et al., 2007).

Epidemiologic studies performed to detect Microcystins intoxication with sub-lethal and prolonged exposure to cyanobacteria failed to describe a quantitative relationship between microcystin concentration in plasma and injury extention. Chen et al. (2009) demonstrated a positive correlation between the concentration of MCs in serum with liver damage markers such as the pyruvic- and glutamic-transaminases (AST, ALT) and the gammaglutamyl-transpeptidase $(\gamma-G T)$ activities in samples from fishermen exposed for 10 years to elevated levels of cyanobacteria.

However, human, wild and domestic animals' prolonged exposure to sub-lethal levels of MCs is likely to be unnoticed. Studies in rat (Guzman and Solter, 2002) and mouse models (Andrinolo et al., 2008) showed that body weight, symptomatology and behavior of MC-LR prolonged treated animals were not different from control ones. This may explain why sub-chronic intoxication of humans and animals is currently not detected. Because of this, the search of biomarkers of MCs prolonged sub-lethal exposure needs to be explored.
In order to provide tools (such as biomarkers of damage) that will facilitate epidemiological studies, we aimed to study the MC-LR action at the systemic (plasma) level in a mouse model previously used to investigate the toxic effect(s) of cyanotoxins (Andrinolo et al., 2008; Sedan et al., 2010). Various biomarkers of exposure and damage were determined in samples of MC-LR i.p.-treated mice as putative tools to be implemented in large human screening and/or animal studies.

\section{Materials and methods}

\subsection{Microcystin-LR purification}

MC-LR was purified from natural blooms of Microcystis aeruginosa collected at the Río de la Plata basin by established methods (Barco et al., 2002) with slight modifications. Firstly, cells were broken by sonication (Omni-Ruptor $400,15 \mathrm{~min}$ ) and the extract was cut with chloroform/ methanol (50:50; v:v). The aqueous fraction was concentrated in a rotovapor (Decalab, R-23, Buenos Aires, Argentina). Purification was performed with a semipreparative high-performance liquid chromatography. We used a Shimadzu 20A HPLC apparatus with a degassed module and a diode array detector system for detection at $238 \mathrm{~nm}$. The preparative column used was TERMO Hyperprep HS C18 $(250 \times 10 \mathrm{~mm})$ and the mobile phase was deionized water (TFA $0.05 \%$ ) with $35 \%$ acetonitrile (TFA $0.05 \%$ ) run in isocratic conditions at $5 \mathrm{~mL} / \mathrm{min}$. The peak corresponding to MC-LR was collected separately, concentrated with a previously activated C18 cartridge. Pure MCLR was eluted with a solution of methanol:water (90:10, $\mathrm{v}: \mathrm{v})$ and methanol was evaporated. The toxin was tested by HPLC-MS method (Barco et al., 2002). Final identification and concentration of MC-LR were achieved by comparison with a Sigma Chemical Inc. toxin standard (St. Louis, MO).

\subsection{Mice and treatment}

Male mice N:NIH-S (20-22 g) with specific pathogenfree certified status were obtained from the Animal Care Facility Unit of the Veterinary Medicine School of La Plata National University. They were housed in plastic cages (four animals in each) and fed ad libitum with balanced food (Alimentos Ganave, Rosario, Argentina) and water. Animals were maintained on a 12-h-light/darknes cycle and allowed to acclimatize to their surrounding conditions (well-ventilated room maintained at $23 \pm 1^{\circ} \mathrm{C}$ ) for 1 week before experiments started. Studies were conducted in accordance with international protocols for laboratory animal care (National Research Council, 1985). Experimental designs were also approved by the local standard for protecting animal's welfare.

\subsection{Experimental design}

\subsubsection{MC-LR distribution and prolonged exposure}

The experimental protocol involved three types of treatments. A group of mice was injected intraperitoneally (i.p.) with a single dose of $25 \mu \mathrm{g}$ MC-LR $/ \mathrm{kg}$ of body weight (group 1). Other group of animals was i.p. treated with 
$25 \mu \mathrm{g}$ MC-LR/kg bw every 48 h during a week (four total injections, group 2), and other group was injected with the same dose and frequency during a month (fifteen total injections, group 3). This dose is approximately half of the LD50 dose (Chen et al., 2006). The toxin was freshly prepared by dilution of the stock preparation with saline solution (0.9\%; w/v). Control group was injected with the equivalent volume of saline solution.

Animals exposed to a single dose and controls were sacrificed at $30 \mathrm{~min}, 3 \mathrm{~h}$ and $24 \mathrm{~h}$ post-injection (group 1). Animals of group 2 and 3 were sacrificed $24 \mathrm{~h}$ after final injection. Blood samples were obtained from these animals by intracardiac puncture. Liver and kidney tissues were dissected, washed, and weighed. Additionally for animals of group 2 urine and feces samples were collected. To minimize diurnal variations, all animals were routinely killed between 12:00 and 13:00 pm.

\subsection{Analytical determinations}

\subsubsection{MC-LR determination}

MC-LR was determined in plasma, liver, kidney, urine and feces. MC-LR extraction from samples was carried out following the technique described by Soares et al. (2006) and MC-LR analyses were performed using commercially available ELISA plate kits (Envirologix Inc., Portland, ME, USA). Concentrations were expressed as MC-LR equivalents.

\subsubsection{Biochemical parameters}

Blood was collected in heparinized tubes and immediately centrifuged at $5000 \mathrm{~g}$ for $5 \mathrm{~min}$. Plasma fractions were separated and analyzed for alkaline phosphatase (ALP), alanine transaminase (ALT), total bilirrubine $(\mathrm{Bb})$ levels (commercial kits, Wiener Laboratory, Rosario, Argentina).

\subsubsection{Lipid analysis}

Plasma total lipids (TL) were extracted according to the method of Folch et al. (1957). Individual lipid subclasses were separated using high-performance thin layer chromatography (HP-TLC) on pre-coated silicagel plates $(10 \times 20 \mathrm{~cm})$ from Whatman Schleicher and Schuell (CA, USA). Mobile phase was chloroform: methanol: ammonium hydroxide (65:25:4). Authentic standards mixtures of neutral (NL) and polar lipids (PL) were run in parallel (Avanti Polar Lipids Inc.; NY, USA). Spots were visualized using iodine vapor, Coomassie brilliant blue R-250 reagent (Nakamura and Handa, 1984), or charring procedure $\left(\mathrm{FeCl}_{3}-\mathrm{H}_{2} \mathrm{SO}_{4}\right)$ (Kritchevsky et al., 1973) produced similar results. Quantification was accomplished by a densitometric procedure (Marra and de Alaniz, 1992) using the 1D Image Analysis Software, Windows ver. 2.0.3 from Eastman Kodak Company (Rochester, NY) followed by phosphorus determination according to Chen et al. (1956). Cholesterol (CHO) content was enzymatically measured according to Allain et al. (1974). Triacylglyceride (TAG) content was assayed using a kit from Wienner Lab. (Rosario, Argentina). Total fatty acid methyl esters (FAMEs) were prepared with $14 \%(\mathrm{~W} / \mathrm{V})$ boron trifluoride-methanol following the method of Morrison and Smith (1964) and analyzed by capillary gas-liquid chromatography (c-GLC) in a Hewlett
Packard HP 6890 Series GC System Plus (Avondale, PA) equipped with a terminal computer integrator. Authentic standards of FAMEs mixtures were routinely run to check the identity of the fatty acids (FAs) analyzed by means of their relative retention times. In some cases, the identity of the FAs was confirmed by means of mass-spectrometry analysis (Marra et al., 2002). A standard procedure for a single-step preparation of dimethyl disulfide adducts of FAs was performed according to Yanamoto et al. (1991). Gasliquid mass-spectrometry analysis of FAs adducts was carried out on a glass column ( $1 \mathrm{~m} \times 3 \mathrm{~mm}$ i.d.) packed with 2\% OV-101 on 100-200 mesh Chromosorb WHP (Supleco, Bellefonte, PA) in a Hitachi 663-30 gas chromatograph linked to a Hitachi M-80A Double-focusing Mass Spectrometer (ionization energies from 20 to $70 \mathrm{eV}$ ) with an M003 minicomputer on-line system. Scan speed was $5 \mathrm{~s}$ per cycle for 0-450 a.m.u. and the column temperature was programmed at $2{ }^{\circ} \mathrm{C} / \mathrm{min}$ from $230{ }^{\circ} \mathrm{C}$ to $260{ }^{\circ} \mathrm{C}$. Perfluorokerosene was used for calibration standard with a power resolution of approx. 6000.

\subsubsection{Oxidative stress biomarkers}

Total plasma hydroperoxides (ROOHs) were measured using the technique by Nourooz-Zadeh et al. (1995) based on the "FOX assay". Methemoglobin was determined in blood samples using the method described by Evelyn and Malloy (1938). Hemoglobin was determined using a commercial kit (Wiener Lab, Rosario, Argentina). Blood smears were stained with May-Grünwald/Giemsa method and observed using an optical microscope (Olympus). Erythrocyte susceptibility to induced hemolysis was estimated following the methodology described by Cheng et al. (2001). Plasma contents of oxidized glutathione (GSSG) were determined following Rahman et al.'s method (2006) whereas reduced glutathione (GSH) was measured following the glutathione-S-transferase recycling assay described by Brigelius et al. (1983). Samples for glutathione analyses were obtained in the presence of N-ethylmaleimide and deproteinized (1:9) using trichloroacetic acid (15\% final concentration) as recommended by Asensi et al. (1994). Erythrocyte superoxide dismutase activity (SOD) was assayed as described by Flohé and Ötting (1984) and catalase activity was measured according to the UV kinetic method of Aebi (1984). Plasma $\alpha$-Tocopherol content was determined by HPLC following Buttris and Diplock's method (1984). HPLC analyses were performed in a Merck-Hitachi apparatus (Darmstadt, Germany) equipped with an L-6200 Solvent Delivery System and an L4200 UV/VIS Detector. We used a A-250 $\times 4.6 \mathrm{~mm}$ Econosil C-18 column (Alltech Associates, Deerfield, IL) coupled to a $10 \times 4 \mathrm{~mm}$ guard column (packed similarly) run isocratically at $1.5 \mathrm{~mL} / \mathrm{min}$. Plasma protein content was determined by Bradford micromethod (1976) with crystalline Bovine Serum Albumin as standard.

\subsection{Statistical treatment}

All samples were processed individually. The data represent the mean of at least 6 individual determinations (assayed in duplicate or triplicate) \pm 1 standard deviation (SD). The statistical significance of data was analyzed by 
either the Student's t-test or by ANOVA (analysis of variance) plus Bonferroni test, with the aid of Systat (version 12.0 for Windows) from SPSS Science (Chicago, IL). Data were plotted and analyzed using Origin (version 8.0) and/or GB-STAT Professional Statistics Program (version 4.0) from Dynamic Microsystems Inc. (Silver Springs, USA).

\section{Results}

In previous works we reported alterations in liver weights normalized to body weight, ALT and ALP activities produced by MC-LR i.p. administration. In this paper we use the increase of these parameters and $\mathrm{Bb}$ levels as signal of a hepatotoxic condition that lets us correlate plasma parameters with MC-LR prolonged exposure in a well characterized animal model.

We found that after 30 days of treatment, normalized liver weights were higher in treated mice $(1.5 \pm 0.1 \%)$ respect to control ones $(1.0 \pm 0.1 \%)$. Also, ALT was 3.5 fold, ALP was 3 fold, and $\mathrm{Bb}$ was 3.3 fold higher than control values. These results strongly suggest hepatic damage induced by MC-LR.

\subsection{MC-LR distribution}

Various times after MC-LR i.p. administration, toxin detection was performed in plasma, liver and kidney of treated mice (group 1) (Fig. 1). After 30 min post-injection highest plama levels (44.8 $\pm 0.3 \mathrm{ng}$ MC-LReq/ml; $N=6)$ of MC-LR were detected. In kidney $(38.6 \pm 1.6 \mathrm{ng}$ MC-LReq/gr; $N=6)$ and liver $(9.4 \pm 1.4 \mathrm{ng}$ MC-LReq/gr; $N=6)$ tissues, concentrations of the toxin were lower than those observed in plasma. Three hours after injection there was a change in the pattern of toxin distribution characterized by a decrease of MC-LR concentration in plasma $(21.7 \pm 0.1 \mathrm{ng}$ MC-LReq/ $\mathrm{ml} ; N=6)$ and kidney ( $8.6 \pm 1.2 \mathrm{ng}$ MC-LReq/gr; $N=6$ ) without significant increase in liver $(11.1 \pm 1.2 \mathrm{ng}$ MC-LReq/ gr; $N=6$ ) (especially in comparison to those values measured at 30 min after administration). After $24 \mathrm{~h}$ postinjection, MC-LR plasma levels $(6.4 \pm 2.2 \mathrm{ng}$ MC-LReq $/ \mathrm{ml}$; $N=6$ ) were significantly lower than those observed in early stages, while the levels observed in kidney $(10.5 \pm 1.5 \mathrm{ng}$ MCLReq/gr; $N=6$ ) showed no significant changes (Fig. 1 ).

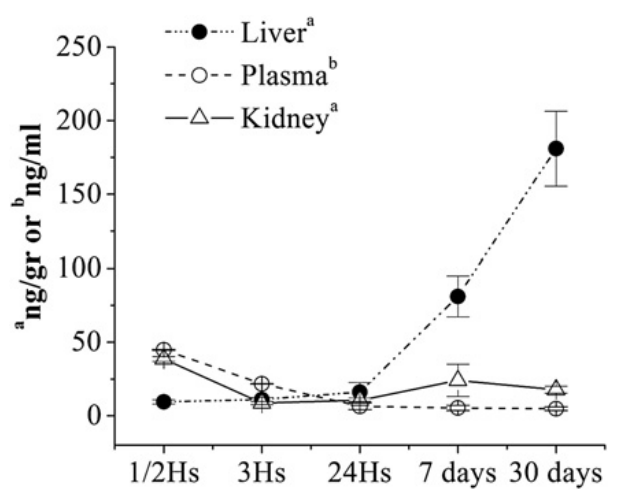

Fig. 1. Liver, kidney and plasma levels of MC-LR vs time in mice exposed to MC-LR, performed by ELISA test (mean $\pm \mathrm{SD}, N=6$ ).
On the other hand, the results obtained after one week (group 2) reflect the effect of 4 injections of $25 \mu \mathrm{g} \mathrm{MC-LR/kg}$ body weight, performed every $48 \mathrm{~h}$. Liver is the main organ for toxin accumulation, toxin levels $(81.1 \pm 13.1 \mathrm{ng}$ MC-LReq/ g; $N=6$ ) are even higher than those detected at earlier times. The values observed in kidney $(24.1 \pm 10.9 \mathrm{ng}$ MCLReq/g; $N=6$ ) and plasma (5.3 $\pm 1.8 \mathrm{ng}$ MC-LReq/ml; $N=6$ ) were similar to those measured after $24 \mathrm{~h}$ post-injection. Similarly, after 1 month of MC-LR exposure (15 i.p. administrations every $48 \mathrm{~h}$ ) liver (181.0 $\pm 25.5 \mathrm{ng}$ MC-LReq/g; $N=6$ ) was the preferred organ for toxin accumulation. Additionally, we have determined the amount of MC-LR in samples of urine and feces in one week exposed animals. The results indicated the presence of MC-LR in urine (34.2 $\pm 10.1 \mathrm{ng}$ MC-LReq/mL urine) and feces $(14.9 \pm 9.5 \mathrm{ng}$ MC-LReq/g) in mice treated during a week.

\subsection{Plasma hydroperoxides levels}

We also studied plasma hydroperoxide levels in one month treated and control animals in order to detect whether there was a peripheral biomarker of oxidative stress induced by MC-LR administration. Hydroperoxide levels (Fig. 2) - determined by the FOX assay - were observed significantly elevated in plasma of mice exposed to MC-LR sub-chronically (3.8 $\mu \mathrm{g} / \mathrm{mg}$ protein \pm 1.2 ) compared with control group $(1.4 \mu \mathrm{g} / \mathrm{mg}$ protein \pm 0.6$)$.

\subsection{Methemoglobin and erythrocyte characteristics}

The levels of methemoglobin (MetHb) - the oxidized form of $\mathrm{Hb}$ - were determined on one month treated (group 3) and control animals, and normalized to total hemoglobin ( $\mathrm{Hb}$ ) levels (Fig. 3). Although there were no significant variations in the values of total $\mathrm{Hb}$, MetHb levels significantly increased in mice exposed sub-chronically to MC-LR (14.7 $\pm 3.8 \%$ ) compared to control group ( $5.2 \pm 2.5 \%)$ (Fig. 3). There were no morphological alterations of erythrocyte. Also, susceptibility to hemolysis tested in animals

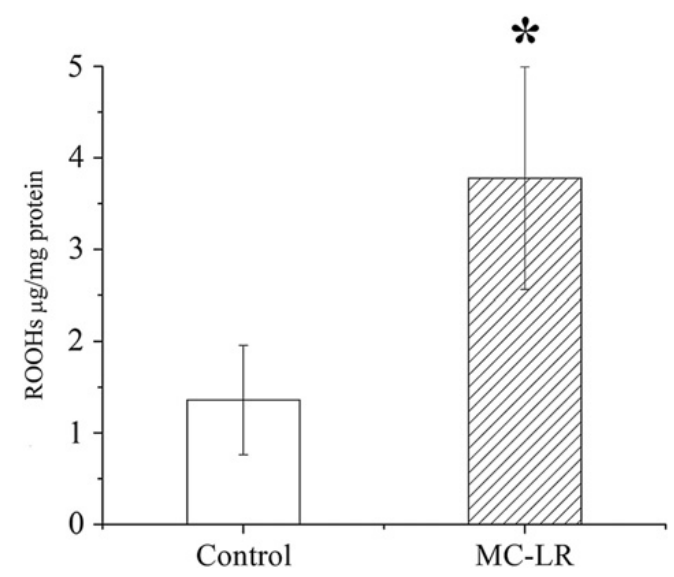

Fig. 2. Plasma hydoperoxides (ROOHs) level measured by the FOX assay in control (white bar) and one month MC-LR treated mice (group 3, dashed bar) (mean $\pm \mathrm{SD}, N=8$ ). The standard error of each mean is shown by bars. * Represents significant difference in control values according to ANOVA test of two independent populations ( $p<0.05 \%)$. 


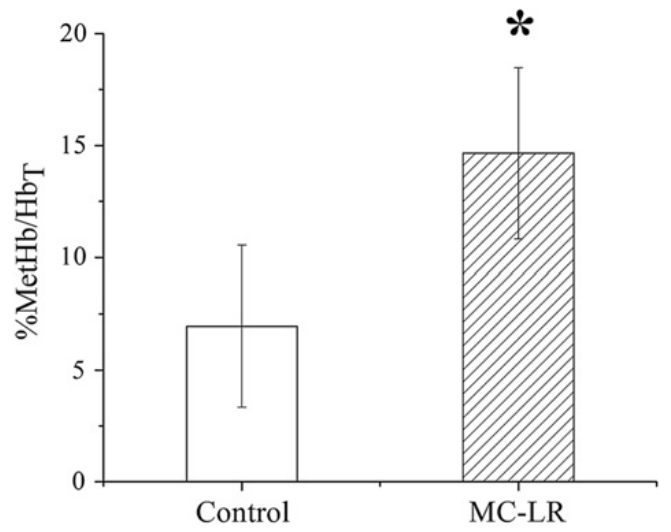

Fig. 3. Methemoglobin (MetHb) level in control (white bars) and one month MC-LR treated mice (dashed bars). Results were expressed as MetHb percentage normalized by total hemoglobin $\left(\mathrm{Hb}_{\mathrm{T}}\right)$ and they were the mean $\pm \mathrm{SD}$ of twelve independent determinations assayed in triplicate. *: Significantly different from the corresponding control value $(p<0.05)$.

treated with MC-LR was indistinguishable from control ones (data not shown).

\subsection{Plasma lipid profile}

Table 1 presents the results of major lipid classes in plasma of control and one month treated animals (group 3) and the main analytical parameters derived from them. We found significant increases in polar and neutral lipid levels in plasma from exposed animals compared to control ones. These changes result in a significant increase in total lipids in plasma of prolonged exposed mice. Also, the ratios total/ neutral lipids (TL/NL) and polar/neutral lipids (PL/NL) showed alterations in plasma from treated animal compared with control mice. Furthermore, we demonstrated diverse alterations of major lipids subclasses. Plasma levels of triacylglyceride (TAG), non-esterified fatty acids (NEFA) and phosphatidylcholine (PhtChol) were significantly higher in mice exposed to MC-LR, while cholesterol-esters (ECHO) plasma levels were reduced (Fig.4).

\section{Table 1}

Major lipids classes in plasma of control and one month exposed mice. Polar lipids included major amounts of PhtChol and PhtEth, minor amounts of sphyngomielin, phosphatidylinositol and cardiolipin, and traces of lysophospholipids. Neurtral lipids included mainly triacylglyceride and cholesterol esters and minor amounts of monoacyl- and diacylglicerides and free cholesterol. Significant differences between exposed animals and the corresponding control group were indicated with an asterisk $(p<0,05)$. Each sample was collected and separately analyzed under the conditions described in the experimental part. Results are the mean of six independent determinations assayed in duplicate $\pm \mathrm{SD}$.

\begin{tabular}{lrc}
\hline & \multicolumn{1}{c}{ Control } & \multicolumn{1}{c}{ MC-LR } \\
\hline Total lipids $^{\mathrm{a}}$ & $116.1 \pm 5.6$ & $181.1 \pm 7.2^{*}$ \\
Polar lipids $^{\mathrm{b}}$ & $81.0 \pm 2.4$ & $115.3 \pm 3.3^{*}$ \\
Neutral lipids & $35.1 \pm 1.8$ & $65.8 \pm 2.4^{*}$ \\
TL/NL & $3.30 \pm 0.2$ & $2.75 \pm 0.5^{*}$ \\
TL/PL & $1.4 \pm 0.1$ & $1.6 \pm 0.2$ \\
PL/NL & $2.3 \pm 0.2$ & $1.7 \pm 0.2^{*}$ \\
\hline
\end{tabular}

\footnotetext{
${ }^{\mathrm{a}} \mathrm{pg} / \mathrm{mg}$ protein.

b pmol inorganic phosphate/mg protein.

c pmol tripalmitine/mg protein.
}
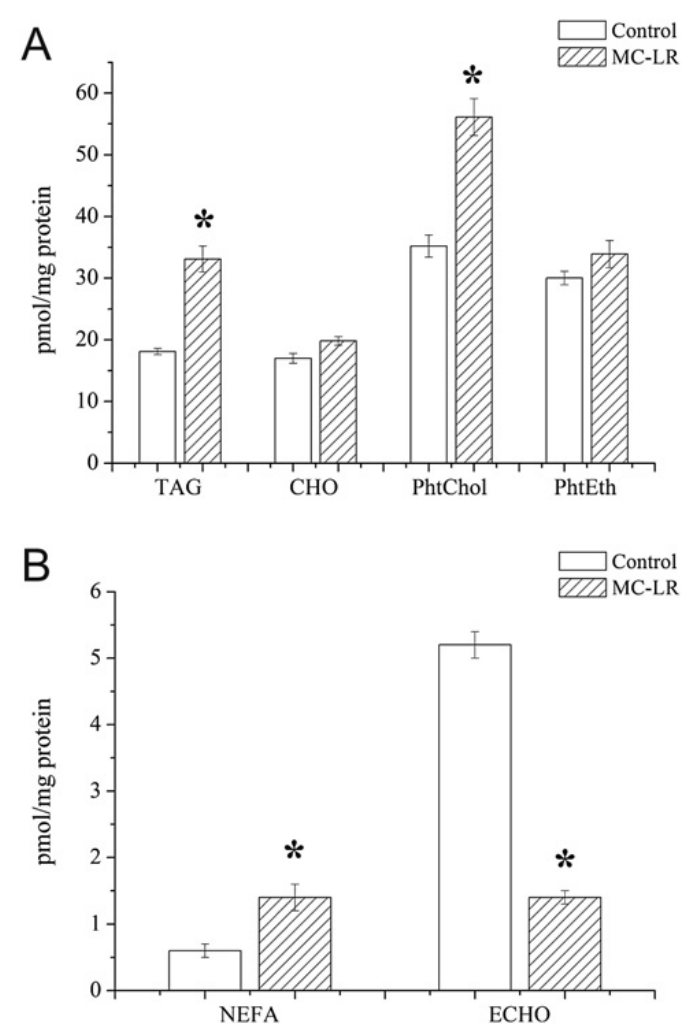

Fig. 4. Major lipid subclasses in plasma from control (white bars), and exposed (dashed bars) animals to MC-LR ( $25 \mu \mathrm{g} / \mathrm{kg}$ body weight) during 30 days. A) Triacylglyceride (TAG): pmole tripalmitine/mg protein; Cholesterol (CHO): pmole/mg protein; Phosphatidylcholine (PhtChol), Phosphatidylethanolamine (PhtEth): pmole inorganic phosphate/mg protein. B) Nonesterified fatty acids (NEFA): pmole of palmitate/mg protein; Cholesterolesters (ECHO): pmole of lynoleyl-cholesterol/mg protein. Each sample was collected and separately analyzed under the conditions described in detail in Materials and methods section. Results are the mean of 6 independent determinations assayed in duplicate \pm SD. Significant differences between exposed animals and the corresponding control group were indicated with an asterisk $(p<0.05)$.

After one month of MC-LR exposure, we observed quantitative modifications on the plasma fatty acyl composition. The toxin produced an increase in saturated FAs (SFA), mainly 18:0, 20:0, 22:0 and 24:0, and reduced levels of monoenoates mainly oleic acid (18:1) (Table 2). Polyunsaturated fatty acids (PUFA) such as arachidonic acid $(20: 4 n-6)$ - and its precursor within the $n-6$ essential series, eicosatrienoate - were both significantly reduced in plasma from treated animals compared to control. Within this group we also found decreased levels of 22:3 $(n-6)$ which derive from the elongation pathway initiated by the 20:3 ( $n-6)$. The $n-3$ essential FAs series also showed alterations during intoxication like increased levels of 21:5 and a decrease in the values of both 22:5 and 22: 6 .

\subsection{Plasma antioxidant system}

As the main components of the antioxidant enzyme system, the activities of catalase (CAT) and superoxide dismutase (SOD) in erythrocytes were tested in control and one month treated animals (group 3). Also $\alpha$-tocopherol, total (Gt), reduced (GSH) and oxidized (GSSG) glutathione levels were determined as the main lipid- and watersoluble antioxidants. 
Table 2

Quantitative fatty acyl composition from control or one month exposed plasma. c-GLC of the fatty acid methyl esters were performed as indicated in Materials and methods section. Plasma samples from control or exposed mice, were separately analyzed ( 6 animals each group). Each value is expressed as $\mathrm{mmol} / \mathrm{mg}$ total protein (mean $\pm 1 \mathrm{SD}$ ). Results for the same fatty acid with an asterisk are significantly different $(p<0.01)$ compared to the corresponding control value. Means below $0.1 \%$ are indicated as "traces". Other fatty acids not consigned in the table were present in negligible amounts. SD below 0.01 are indicated as " 0.0 ".

\begin{tabular}{|c|c|c|}
\hline Fatty acids & Control & MC-LR \\
\hline $14: 0$ & $0.1 \pm 0.01$ & $0.1 \pm 0.03$ \\
\hline $15: 0$ & $0.1 \pm 0.02$ & $0.1 \pm 0.0$ \\
\hline $16: 0$ & $19.1 \pm 0.9$ & $24.4 \pm 0.8$ \\
\hline $16: 1(n-9)$ & $2.0 \pm 0.3$ & $2.0 \pm 0.2$ \\
\hline $16: 1(n-7)$ & $0.1 \pm 0.03$ & $0.3 \pm 0.05$ \\
\hline $17: 0$ & $0.2 \pm 0.03$ & $0.1 \pm 0.04$ \\
\hline $16: 3(n-3)$ & $0.1 \pm 0.01$ & $0.1 \pm 0.0$ \\
\hline $16: 4(n-3)$ & $0.1 \pm 0.0$ & 0.0 \\
\hline $18: 0$ & $15.6 \pm 0.7$ & $20.4 \pm 0.6^{*}$ \\
\hline $18: 1(n-9)$ & $16.1 \pm 0.5$ & $12.4 \pm 0.3^{*}$ \\
\hline $18: 1(n-7)$ & $0.6 \pm 0.2$ & $0.5 \pm 0.3$ \\
\hline $18: 2(n-7)$ & $0.1 \pm 0.05$ & $0.2 \pm 0.04$ \\
\hline $18: 2(n-6)$ & $15.5 \pm 0.5$ & $12.0 \pm 0.6$ \\
\hline $18: 3(n-6)$ & Traces & Traces \\
\hline $18: 3(n-3)$ & $0.1 \pm 0.02$ & $0.1 \pm 0.01$ \\
\hline $18: 4(n-3)$ & Traces & Traces \\
\hline $20: 0$ & $0.1 \pm 0.0$ & $0.4 \pm 0.1^{*}$ \\
\hline $20: 1(\Sigma n-7+n-9)$ & $0.4 \pm 0.05$ & $0.2 \pm 0.04$ \\
\hline $20: 2(n-6)$ & Traces & $0.4 \pm 0.02^{*}$ \\
\hline $20: 3(n-9)$ & Traces & Traces \\
\hline $20: 3(n-6)$ & $3.5 \pm 0.2$ & $1.9 \pm 0.2^{*}$ \\
\hline $20: 4(n-6)$ & $15.7 \pm 0.5$ & $8.7 \pm 0.3^{*}$ \\
\hline $20: 3(n-3)$ & Traces & Traces \\
\hline $20: 4(n-3)$ & $0.2 \pm 0.02$ & $0.1 \pm 0.05$ \\
\hline $20: 5(n-3)$ & Traces & Traces \\
\hline $22: 0$ & $0.1 \pm 0.03$ & $0.5 \pm 0.1^{*}$ \\
\hline $22: 1(n-9)$ & Traces & $0.1 \pm 0.02$ \\
\hline $21: 5(n-3)$ & Traces & $0.1 \pm 0.03^{*}$ \\
\hline $22: 2(n-6)$ & Traces & Traces \\
\hline $22: 3(n-6)$ & $0.4 \pm 0.01$ & $0.1 \pm 0.03^{*}$ \\
\hline $22: 4(n-6)$ & Traces & Traces \\
\hline $22: 5(n-6)$ & Traces & Traces \\
\hline $22: 4(n-3)$ & Traces & Traces \\
\hline $22: 5(n-3)$ & $0.8 \pm 0.01$ & $0.2 \pm 0.02^{*}$ \\
\hline $24: 0$ & Traces & $0.3 \pm 0.03^{*}$ \\
\hline $22: 6(n-3)$ & $5.5 \pm 0.5$ & $3.1 \pm 0.2^{*}$ \\
\hline $24: 1$ & Traces & Traces \\
\hline
\end{tabular}

\subsubsection{Antioxidant enzymes}

We observed a significant increase in erythrocytes SOD activity in mice exposed to MC-LR compared to control ones (Fig. 5A), while CAT activity showed no alterations (Fig. 5B).

\subsubsection{Antioxidants}

Total glutathione (Gt), GSH, and GSSG levels were significantly increased in plasma of animals exposed to MCLR compared to control (Fig. 6). In addition, a decrease in GSH/GSSG ratio was observed in animals treated with MC$\mathrm{LR}(19.5 \pm 1.7 \mu \mathrm{mol} / \mathrm{mg}$ protein $)$ compared with the control group $(31.0 \pm 2.5 \mu \mathrm{mol} / \mathrm{mg}$ protein). This alteration was the consequence of a greater increase of GSSG than GSH (100\% and $26 \%$ respectively) respect to control (Fig. 6). One month after MC-LR exposure, an important decrease in the level of $\alpha$-tocopherol was also observed (Fig. 7).

Consumption of this antioxidant could result from system efforts to counteract the pro-oxidative state induced by
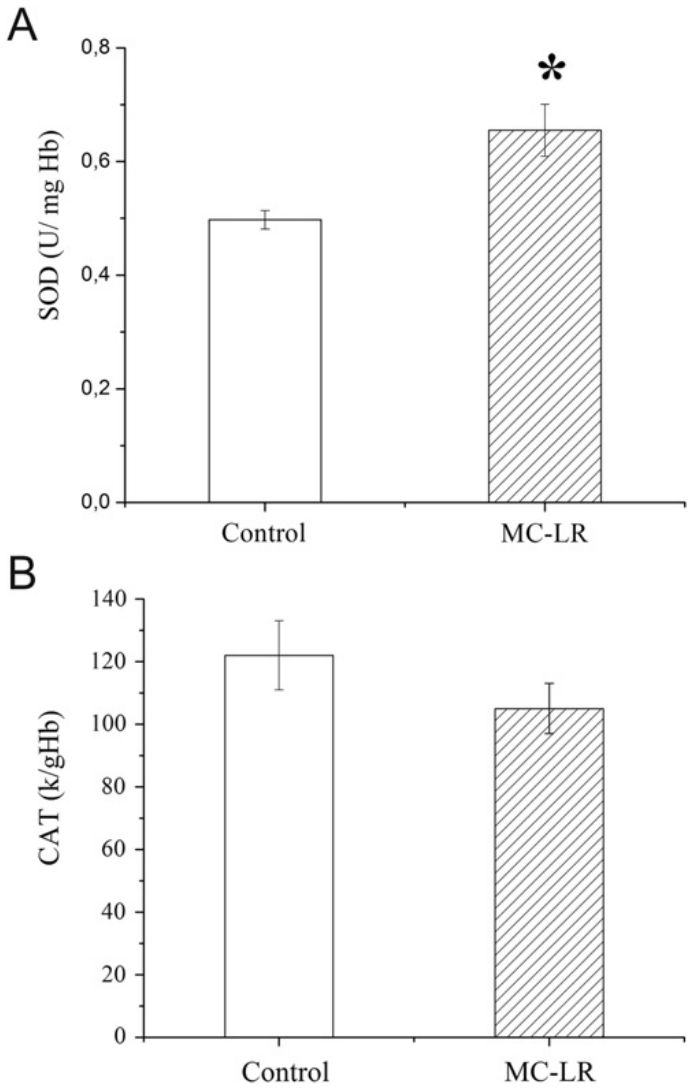

Fig. 5. Superoxide dismutase (A) and catalase (B) activities in erythrocyte from control (white bars) and MC-LR one month exposed (dashed bars) mice. Enzymes were determined as described in Materials and methods section and expressed as the mean \pm SD of eight independent determinations assayed in duplicate. ${ }^{*}$ : Significantly different from the corresponding control value $(p<0.05)$.

MC-LR. Our results indicate that variations of nonenzymatic antioxidant components, glutathione and $\alpha-$ tocopherol correlate positively with those found in previous studies in liver of mice exposed to MC-LR during a month.

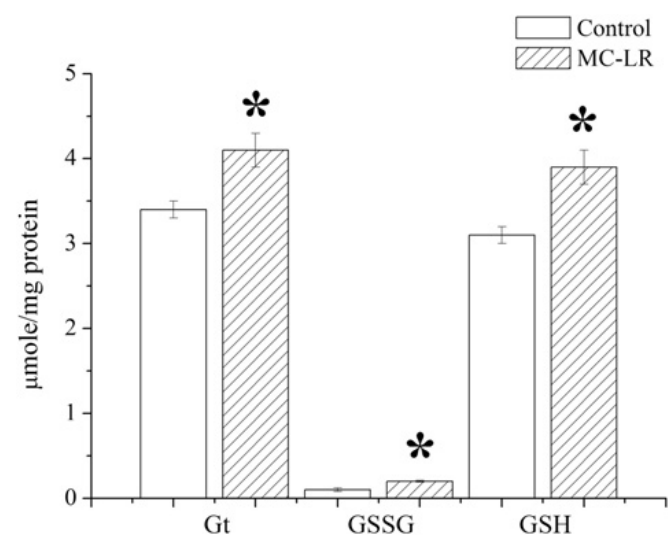

Fig. 6. Total (Gt), reduced (GSH) and oxidized (GSSG) glutathione contents in plasma from control (white bars) and one month exposed (dashed bars) animals to MC-LR (25 $\mu \mathrm{g} / \mathrm{kg}$ body weight). GSH/GSSG ratios were $31.0 \pm 2.5 \mu \mathrm{mol} / \mathrm{mg}$ protein for control group and $19.5 \pm 1.7 \mu \mathrm{mol} / \mathrm{mg}$ protein for treated mice. Results were expressed as mean \pm SD of six independent determinations assayed in duplicate. *: Significantly different from the corresponding control value $(p<0.05)$. 


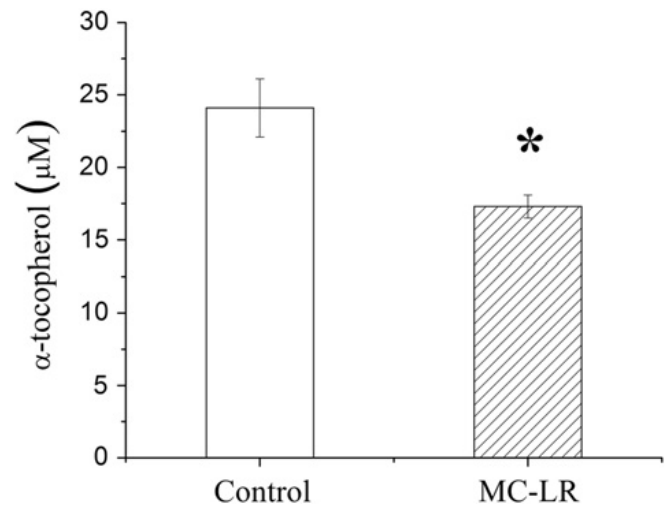

Fig. 7. $\alpha$-Tocopherol content determined in plasma from control (white bars) and one month treated (dashed bars) mice. Results were expressed the mean \pm SD of six independent determinations assayed in triplicate. *: Significantly different from the corresponding control value $(p<0.05)$.

\section{Discussion}

We and other authors have previously demonstrated that MC-LR sub-chronic intoxication induced liver and kindey damage, mainly characterized by lipid peroxidation, alteration of cellular antioxidant systems, protein phosphatase inhibitions, alterations in cytoskeleton and apoptosis (Gehringer, 2004; Andrinolo et al., 2008; Sedan et al., 2010; Lezcano et al., 2012). However, symptoms or signs of intoxication that facilitate their recognition and diagnosis were not expressed.

We demonstrated that MC-LR initially circulates in blood and - at least during the first hour post-injection - it enters into contact with body tissues as kidney. However, after this phase there is a rapid uptake of toxin by the liver. We think that a portion of the total toxin injected could remain covalently conjugated to certain proteins such as protein phosphatases, which probably do not immunoreact against the antibodies used for the ELISA assay. This assumption is in agreement with previously reported experimental evidence (Craig et al., 1996; MacKintosh et al., 1995; Williams et al., 1997). Therefore, in liver and other biological samples, MC-LR levels are likely to be underestimated by using this methodology (Soares et al., 2006). Also in agreement with recent studies performed in acute models of MC-LR intoxication (Lowe et al., 2012) in this work, the toxin was also detected in plasma, urine, and feces of prolonged exposed mice. These results suggest the possibility to detect the toxin in samples easy to obtain (with a minimally invasive procedure). Thus, this could be an interesting biomarker of exposure.

In agreement with Robinson et al. (1991) and Solter et al. (1998), we have determined accumulation of MC-LR in liver of animals treated with $25 \mu \mathrm{g}$ MC-LR/Kg every $48 \mathrm{~h}$ during 1 week and 1 month. Moreover, in previous studies of our group a significant liver damage induced by MC-LR was shown under similar exposure conditions (Andrinolo et al., 2008; Sedan et al., 2010).

It was proposed that liver MCs retention capacity depends on how this organ is affected by the toxin (Runnegar et al., 1987). It is probable that MC-LR accumulation is related with the toxin's ability to inhibit hepatic clearance (Runnegar et al., 1987, 1995).
Accumulation of the toxin may explain -at least in part the effects caused by MC-LR on glutathione system. The conjugation with GSH is one of the main routes of excretion (Kondo et al., 1996) of the toxin. Thus, we can assume an increased demand of GSH in order to facilitate toxin clearance via biliary system. In addition, MC-LR produces a significant oxidative stress condition that reduces the availability of GSH at expense of a higher rate of oxidation to GSSG. These effects are both closely related to alterations in the cytoskeleton structure and functionality as previously reported (Ishii et al., 1991; Hooser et al., 1991).

Due to the nature of the sub-chronic intoxication previously determined by our research group, we studied peripheral blood alterations related to redox status and lipid profile by assessing parameters such as ROOHs, MetHb, SOD, CAT, glutathione, lipids, fatty acids and $\alpha$-tocopherol (Andrinolo et al., 2008; Sedan et al., 2010).

From our best knowledge, this is the first report on the effects produced by MC-LR intoxication on mammalian blood samples. Acute in vivo studies in fish exposed to Microcystis extracts (50 and $200 \mu \mathrm{g}$ MC-LReq/kg, i.p.) demonstrated decreased erythrocyte count, Hb concentration, and hematocrit $(\mathrm{Ht})$ values that match with a normocytic anemia (Zhang et al., 2007). The same study reported increased renal dysfunction parameters BUN (blood urea nitrogen) and creatinine levels. Thus, the observed anemia was associated by authors with renal dysfunction caused by exposure to extracts of MCs in fish. Our results indicated no difference in $\mathrm{Hb}$ values or erythrocytes morphology in MCLR exposed mice. This apparent discrepancy between the results of both studies may be due to differences in species metabolic characteristics and/or variable response after acute or sub-chronic exposure or even the use of Microcystis extracts instead of purified MC-LR. Differences between animal models and the considerably higher doses used in the study with fish in comparison with our model, could be another factor(s) to be take into account. An in vitro study conducted by Sicinska et al. (2006) using human erythrocytes incubated with MC-LR (1-1000 nM for 1, 6,12 and $24 \mathrm{~h}$ ) has reported increased lipid peroxidation, erythrocyte morphological alteration, increased hemolysis and MetHb production. Also, CAT activity was reported elevated in a time-dependent fashion concomitantly with a decrease in SOD activity. In agreement with Sicinska et al. (2006), we observed significant increases in hydroperoxides plasma levels after a month of exposure to the toxin. However, it is probable that this alteration might have other source different from the one suggested by the in vitro study. We hypothesized that in vivo ROOHs hyperproduction would be a secondary effect to the MC-LR-induced liver pro-oxidative damage. We also observed increased MetHb levels in blood of mice exposed to MC-LR as well as those seen in the in vitro study (Sicinska et al., 2006). This fact could be the result of the same pro-oxidative environment induced by MC-LR intoxication and suggest MetHb as a putative (unspecific) biomarker of exposure to the toxin. Sicinska et al. (2006) also reported increased hemolysis at higher doses and incubation times with MC-LR. However, this effect disappears at lower doses, similar to those used in our study. The same scenario could be assumed for the absence of morphological alterations in erythrocytes observed under optical microscopy. 
In the in vitro study (Sicinska et al., 2006) the decrease observed for SOD activity was attributed to covalent binding of MC-LR to thiol residues present in the active site of the SOD isoforms. We speculate that in our system the concentration of MC-LR is not enough to elicit this inhibition; however, it could be sufficient to induce a responsiveness of the antioxidant defense system inducing the main neutralizing enzyme as ROS scavenger. Thus, our results indicate that the alterations observed in the parameters tested are mainly due to side effects arising from liver damage caused by MC-LR rather than a direct action of MC-LR on blood cells, assumption that is supported by the fact that the toxin is quickly clarified from the circulation and maintains low plasmatic levels during prolonged exposure.

Results previously reported indicating MC-LR-induced alterations in liver lipids after sub-chronic exposure (Sedan et al., 2010) are now reflected at peripheral level. This is interesting from the analytical point of view in order to obtain samples for monitoring MC-LR-induced damages with a minimally invasive procedure. The use of plasma as monitoring sample of MC-LR-induced damages is also supported by the alterations we found in other parameters such as oxidized and reduced glutathione, GSSG/GSH ratio, $\alpha$-tocopherol content, and ROOHs levels. All these biomarkers of exposure match with those observed in liver tissue as reported in our previous study (Sedan et al., 2010).

\section{Conclusion}

In conclusion, MCs prolonged and sub-acute intoxications are sub-diagnose. Therefore, it is necessary to develop tools that allow their effective detection and that can be transferred to health care systems in affected areas.

In this work we found ALT, ALP, Bb, MetHb, ROOHs, glutathione, $\alpha$-tocopherol levels, SOD activity and plasma lipid profile alterated. These parameters determined in plasma, together with the detection of MC-LR in plasma or urine, could be used as biomarkers easy to perform in large populations, helpful tools in screening and/or epidemiological studies.

\section{Acknowledgments}

The authors are grateful to Norma Cristalli for her excellent technical assistance. This study was partially supported with grants from CIC, SECYT PICT 21227-53 and CONICET PIP 02617 and 0697, Argentina.

\section{Conflict of interest}

None.

\section{References}

Aebi, H., 1984. Oxygen radicals in biological systems. Meth. Enzymol. 105, 121-126. Nutr. Res. 22: 1265-1273.

Allain, C.C., Poon, L.S., Chan, C.S., Richmond, W., Fu, P.C., 1974. Enzymatic determination of total serum cholesterol. Clin. Chem. 20, 470-475.

Amstrong, B., 1980. The epidemiology of cancer in the people of China. Int. J. Epidemiol. 9, 305-315.
Andrinolo, D., Sedan, D., Telese, L., Aura, C., Masera, S., Giannuzzi, L., Marra, C., Alaniz, M.T., 2008. Recovery after damage produced by subchronic intoxication with the cyanotoxin microcystin LR. Toxicon 51, 457-467.

Annadotter, H., Cronberg, G., Lawton, L., Hansson, H.B., Göthe, U., Skulberg, O.M., 2001. An extensive outbreak of gastroenteritis associated with the toxic cyanobacterium planktothrix agardhii (oscillatoriales, cyanophyceae) in Scania, South Sweden. In: Chorus, I. (Ed.), Cyanotoxins. Springer, Berlin, pp. 200-208.

Asensi, M., Sastre, J., Pallardo, F.V., García de la Asunción, J., Estrela, J.M., Viña, J., 1994. A high-performance liquid chromatography method for measurement of oxidized glutathion in biological samples. Anal. Biochem. 217, 323-328.

Barco, M., Rivera, J., Caixach, J., 2002. Analysis of cyanobacterial hepatotoxins in water samples by microbore reversed-phase liquid chromatography-electrospray ionisation mass spectrometry. J. Chromatogr. A 959, 103-111.

Bell, S.G., Codd, G.A., 1994. Cyanobacterial toxins and human health. Rev. Med. Microbiol. 5 (4), 256-264.

Bradford, M.M., 1976. A rapid and sensitive method for quantitation of microgram quantities of protein utilizing the principle of proteindye-binding. Anal. Biochem. 72, 248-254.

Brigelius, R., Muckel, C., Akerboom, T.P., Sies, H., 1983. Identification and quantitation of glutathione in hepatic protein mixed disulfides and its relationship to glutathione disulfide. Biochem. Pharmacol. 32, 25292534.

Buttriss, J.L., Diplock, A.T., 1984. High-performance liquid chromatography methods for vitamin E in tissues. Methods Enzymol. 105, 131-138.

Carmichael, W.W., 1994. The toxins of cyanobacteria. Sci. Am. 270 (1), 78-86.

Carmichael, W.W., 1997. The cyanotoxins. In: Callow, J. (Ed.), 1997. Advances in Botanical Research, vol. 27. Academic Press, London, pp. 211-256.

Cazenave, J., Bistoni, M.A., Pesce, S.F., Wunderlin, D.A., 2006. Differential detoxification and antioxidant response in diverse organs of Corydoras paleatus exposed to Microcystin-RR. Aquat. Toxicol. 76, 1-12.

Chen, P.S., Toribara, T.Y., Warner, H., 1956. Microdetermination of phosphorus. Anal. Chem. 28, 1756-1758.

Chen, Y.M., Lee, T.H., Lee, S.J., Huang, H.B., Huang, R., Chou, H.N., 2006. Comparison of protein phosphatase inhibition activities and mouse toxicities of microcystins. Toxicon 47, 742-746.

Chen, J., Xie, P., Li, L., Jun, X., 2009. First identification of the hepatotoxic microcystins in the serum of a chronically exposed human population together with indication of hepatocellular damage. Toxicol. Sci. 108, 81-89.

Cheng, T.Y., Zhu, Z., Masuda, S., Morcos, N.C., 2001. Effects of multinutrient supplementation on antioxidant defence systems in healthy human being. J. Nutr. Biochem. 12, 388-395.

Craig, M., Luu, H.A., McCready, T.L., Williams, D., Andersen, R.J., Holmes, C.F., 1996. Molecular mechanisms underlying the interaction of motuporin and microcystins with type- 1 and type-2A protein phosphatases. Biochem. Cell. Biol. 74, 569-578.

Dietrich, D., Ernest, B., Day, B., 2007. Human consumer death and algal supplement consumption: a post mortem assessment of potential microcystin-intoxication via microcystin inmunohistochemical (MCIHC) analyses. In: Oral Presentation 7th International Conference of Toxic Cyanobacteria. Brasil; 132.

Ding, W., Ong, C., 2003. Role of oxidative stress and mitochondrial changes in cyanobacteria-induced apoptosis and hepatotoxicity. FEMS Microbiol. Lett. 220, 1-7.

Ding, W.X., Shen, H.M., Zhu, H.G., Ong, C.N., 1998. Studies on oxidative damage induced by cyanobacteria extract in primary cultured rat hepatocytes. Environ. Res. 78 (1), 12-18.

Ding, W.X., Shen, H.M., Zhu, H.G., Lee, B.L., Ong, C.N., 1999. Genotoxicity of microcystic cyanobacteria extract of a water source in China. Mutat. Res. 442, 69-77.

Ding, W.X., Shen, H.M., Ong, C.N., 2000. Microcystic cyanobacteria extract induces cytoskeletal disruption and intracellular glutathione alteration in hepatocytes. Environ. Health Perspect. 108 (7), 605-609.

Ding, W.X., Shen, H.M., Ong, C.N., 2001. Pivotal role of mitochondrial $\mathrm{Ca}(2+)$ in microcystin-induced mitochondrial permeability transition in rat hepatocytes. Biochem. Biophys. Res. Commun. 285 (5), 11551161.

Evelyn, K.A., Malloy, H.T., 1938. Microdetermination of oxyhemoglobin, methemoglobin and sulphemoglobin in a single sample of blood. J. Biol. Chem. 126, 655-662.

Falconer, I.R., 1991. Tumor promotion and liver injury caused by oral consumption of cyanobacteria. Environ. Toxicol. Water Qual. 6, 177184. 
Falconer, I.R., Humpage, A.R., 1996. Tumor promotion by cyanobacterial toxins. Phycologia 35 (6), 74-79.

Flohé, L., Ötting, F., 1984. Superoxide dismutase assays. Methods Enzymol. 105, 93-104.

Folch, J., Lees, M., Sloane Stanley, G.H., 1957. A simple method for the isolation and purification of total lipids from animal tissues. J. Biol. Chem. 226, 497-509.

Gehringer, M.M., 2004. Microcystin-LR and okadaic acid-induced cellular effects: a dualistic response. FEBS Lett. 57 (1-3), 1-8.

Giannuzzi, L., Sedan, D., Echenique, R., Andrinolo, D., 2011. An acute case of intoxication with cyanobacteria and cyanotoxins in recreational water in Salto Grande Dam, Argentina. Mar. Drugs 9.

Guzman, R.E., Solter, P.F., 2002. Characterization of sublethal MCLR exposure in mice. Vet. Pathol. 39 (1), 17-26.

Guzman, R.E., Solter, P.F., Runnegar, M.T., 2003. Inhibition of nuclear protein phosphatase activity in mouse hepatocytes by the cyanobacterial toxin microcystin-LR. Toxicon 41 (7), 773-781.

Hooser, S.B., Beasley, V.R., Waite, L.L., Kuhlenschmidt, M.S., Carmichael, W.W., Haschek, W.M., 1991. Actin filament alterations in rat hepatocytes induced in vivo and in vitro by microcystin-LR, a hepatotoxin from the blue-green alga, Microcystis aeruginosa. Vet. Pathol. 28 (4), 259-266.

Ishii, M., Washioka, H., Tonosaki, A., Toyota, T., 1991. Regional orientation of actin filaments in the pericanalicular cytoplasm of rat hepatocytes. Gastroenterology 101, 1663-1672.

Ito, E., Kondo, F., Terao, K., Harada, K., 1997. Neoplastic nodular formation in mouse liver induced by repeated intraperitoneal injections of MCLR. Toxicon 35 (9), 1453-1457.

Jochimsen, E.M., Carmichael, W.W., An, J., Denise, M.C., Cookson, S.T., Holmes, C.E.M., Antunes, M.B.C., Melo, F.D.A., Lyra, T.M., Barreto, V.S.T., Azevedo, S.M.F.O., Jarvis, W.R., 1998. Liver failure and death after exposure to microcystins at a hemodialysis center in Brazil. N. Engl. J. Med. 338 (13), 873-878.

Kondo, F., Matsumoto, H., Yamada, S., Ishikawa, N., Ito, E., Nagata, S., Ueno, Y., Suzuki, M., Harada, K., 1996. Detection and identification of metabolites of microcystins formed in vivo in mouse and rat livers. Chem. Res. Toxicol. 9, 1355-1359.

Kritchevsky, D., Davidson, L.M., Kim, H.K., Malhotra, S., 1973. Quantitation of serum lipids by a simple TLC-charring method. Clin. Chim. Acta 46, 63-68.

Lezcano, N., Sedan, D., Lucotti, I., Giannuzzi, L., Vittone, L., Andrinolo, D., Mundiña-Weilenmann, C., 2012. Subchronic Microcystin-LR exposure increased hepatic apoptosis and induced compensatory mechanisms in mice. J. Biochem. Mol. Toxicol. 26 (4), 131-138.

Lippy, E.C., Erb, J., 1976. Gastrointestinal illness at Sewickley, PA. J. Am. Water Works Assoc. 68, 606-610.

Lowe, J., Souza-Menezes, J., Freire, D.S., Mattos, L.J., Castiglione, R.C., Barbosa, C.M.L., Santiago, L., Ferrão, F.M., Cardoso, L.H.D., da Silva, R.T., Vieira-Beiral, H.J., Vieyra, A., Morales, M.M., Azevedo, S.M.F.O., Soares, R.M., 2012. Single sublethal dose of microcystin-LR is responsible for different alterations in biochemical, histological and physiological renal parameters. Toxicon 59, 601-609.

MacKintosh, R.W., Dalby, K.N., Campbell, D.G., Cohen, P.T., Cohen, P. MacKintosh, C., 1995. The cyanobacterial toxin microcystin binds covalently to cysteine-273 on protein phosphatase 1 . FEBS Lett. 371, 236-240.

Marra, C.A., de Alaniz, M.J.T., 1992. Incorporation and metabolic conversión of saturated and unsaturated fatty acids in SK-Hep1 human hepatoma cells in culture. Mol. Cell. Biochem. 117, 107-118.

Marra, C.A., Zaidenmerg, A., de Alaniz, M.J.T., Buschiazzo, H., 2002. The restoring effect of trifluralin and benznidazole on the abnormal fattyacid pattern induced by Trypanosoma cruzi in the liver microsomes of infected mice. Ann. Trop. Med. Pharmacol. 96, 249-264.

Moreno, I., Repetto, G., y Cameán, A., 2003. Interés toxicológico de las microcistinas. Rev. Toxicol. 20, 159-165.

Morrison, W.R., Smith, L.M., 1964. Preparation of fatty acid methyl esters and dimethylacetals from lipids with boron fluoride-methanol. J. Lipid Res. 5, 600-608.

Nakamura, K., Handa, S., 1984. Coomasie brilliant blue staining of lipids on thin-layer plates. Anal. Biochem. 142, 406-410.

National Research Council, 1985. Guide for the Use and Care of Laboratory Animals. Publication No. 85-23 (rev.). National Institutes of Health, Bethesda, MD.

Nourooz-Zadeh, J., Tajaddimi-Sarmandi, J., McCarthy, S., Betteridge, D.J., Wolff, S.P., 1995. Elevated levels of authentic plasma hydroperoxides in NIDDM. Diabetes 44, 1054-1058.

Ohta, T., Nishiwaki, R., Yatsunami, J., Komori, A., Suganuma, M., Fujiki, H., 1992. Hyperphosphorylation of cytokeratins 8 and 18 by microcystin-
LR, A new liver tumor promotor, in primary cultures of rats. Carcinogenesis $13,2443-2447$.

Rahman, T., Kode, A., Biswas, S.K., 2006. Assay for quantitative determination of glutathione and glutathione disulfide levels using enzymatic recycling method. Nat. Protoc. 1, 3159-3165.

Robinson, N.A., Pace, J.G., Matson, C.F., Miura, G.A., Lawrence, W.B., 1991. Tissue distribution, excretion and hepatic biotransformation of MCLR in mice. J. Pharmacol. Exp. Ther. 256 (1), 176-182.

Runnegar, M.T.C., Andrews, J., Gerdes, R.G., Falconer, I.R., 1987. Injury to hepatocytes induced by a peptide toxin from the cyanobacterium Microcystis aeruginosa. Toxicon 25, 1235-1239.

Runnegar, M., Berndt, N., Kaplowitz, N., 1995. Microcystin uptake and inhibition of protein phosphatases: effects of chemoprotectants and self-inhibition in relation to known hepatic transporters. Toxicol. Appl. Pharmacol. 134, 264-272.

Sedan, D., Andrinolo, D., Telese, L., Giannuzzi, L., Alaniz, M.T., Marra, C.A., 2010. Alteration and recovery of the antioxidant system induced by sub-chronic exposure to microcystin-LR in mice: its relation to liver lipid composition. Toxicon 55, 333-342.

Sicinska, P., Bukowska, B., Michałowicz, J., Duda, W., 2006. Damage of cell membrane and antioxidative system in human erythrocytes incubated with microcystin-LR in vitro. Toxicon 47, 387-397.

Sivonen, K., Jones, G., 1999. Cyanobacterial toxins. In: Chorus, Bertram, J. (Eds.), Toxic Cyanobacteria in Water: a Guide to Public Health Significance, Monitoring and Management.

Soares, R., Yuan, M., Servaites, J., Delgado, A., Magalhaes, V., Hilborn, E., Carmichael, W., Azevedo, S., 2006. Sublethal exposure from microcystins to renal insufficiency patients in Rio de Janeiro, Brazil. Environ. Toxicol. 21, 95-103.

Soares, R., Cagido, V., Ferraro, R., Meyer-Fernandes, J., Rocco, P., Zin, W., Azevedo, S., 2007. Effects of microcystin-LR on mouse lungs. Toxicon $50,330-338$.

Solter, P., Wollenberg, G., Huang, X., Chu, F., Runnegar, M., 1998. Prolonged sublethal exposure to the protein phosphatase inhibitor, microcystinLR results in multiple dosedependant hepatotoxic effects. Toxicol. Sci. $44,87-96$

Teixera, M., Costa, M., Carvalho, V., Pereira, M., Hage, E., 1993. Gastroenteritis epidemic in the area of the Itaparica Dam, Bahia, Brazil. Bull. Pan Am. Health Org. 27, 244-253.

Tisdale, J., 1931. Epidemic of intestinal disorders in Charleston (West Virginia) occurring simultaneously with unprecedented water supply conditions. Am. J. Pub Health 21, 198-200.

Toivola, D.M., Eriksson, J.E., Brautigan, D.L., 1994. Identification of protein phosphatase $2 \mathrm{~A}$ as the primary target for microcystin-LR in rat liver homogenates. FEBS Lett. 344, 175-180.

Turner, P.C., Gammie, A.J., Hollinrake, K., Codd, G.A., 1990. Pneumonia associated with cyanobacteria. Br. Med. J. 300, 1440-1441.

WHO, 2004. Guidelines for Drinking-water Quality. In: Recommendations Chemical Fact. Sheets, third ed., vol. 1. World Health Organization, Geneva, Switzerland, pp. 407-408.

Williams, D.E., Craig, M., Dawe, S.C., Kent, M.L., Holmes, C.F.B., Andersen, R.J., 1997. Evidence for a covalently bound form of microcystin-LR in salmon liver and dungeness crab larvae. Chem. Res. Toxicol. 10, 463-469.

Xia, 2002. Primary Liver Cancer, 30. China Academic Publishers, New York, pp. 674-682.

Yanamoto, K., Shibahara, A., Nakayama, T., Kajimoto, G., 1991. Determination of double-bond positions in methylene-interrupted dienoic fatty acids by GC-MS as their dimethyl disulfide adducts. Chem. Phys. Lipids 60, 39-50.

Yoshizawa, S., Matsushima, R., Watanabe, M.F., Harada, K., Ichihara, A., Carmichael, W.W., Fujiki, H., 1990. Inhibition of protein phosphatases by microcystis and nodularin associated with hepatotoxicity. J. Cancer Res. Clin. Oncol. 116 (6), 609-614.

Yu, S., 1989. Drinking water and primary liver cancer. In: Tang, Z., Wu, M., Xia, S.-S. (Eds.), Primary Liver Cancer. Spring-Verlag, Berlin, pp. 30-37.

Yu, S.-J., 1995. Primary prevention of hepatocellular carcinoma. J. Gastroenterol. Hepatol. 10, 674-682.

Zhang, X., Xie, P., Lia, D., Shi, Z., 2007. Hematological and plasma biochemical responses of crucian carp (Carassius auratus) to intraperitoneal injection of extracted microcystins with the possible mechanisms of anemia. Toxicon 49, 1150-1157.

Zhao, Y., Xieb, P., Zhang, X., 2009. Oxidative stress response after prolonged exposure of domestic rabbit to a lower dosage of extracted microcystins. Environ. Toxicol. Pharmacol. 27, 195-199.

Zilberg, B., 1966. Gastroenteritis in Salisbury European children - a five year study. Centr Afr. J. Med. 12, 164-168. 